extintos planes de estudio de la licenciatura en Historia del Arte, y en los últimos del Título de Grado, lo que vie- ne a confirmar que también en estos asuntos como en la vida, los primeros amores... nunca se olvidan.

\title{
La memoria cultural en la obra y el pensamiento de Rosario Camacho
}

\author{
María Sánchez Luque \\ CCHS-CSIC
}

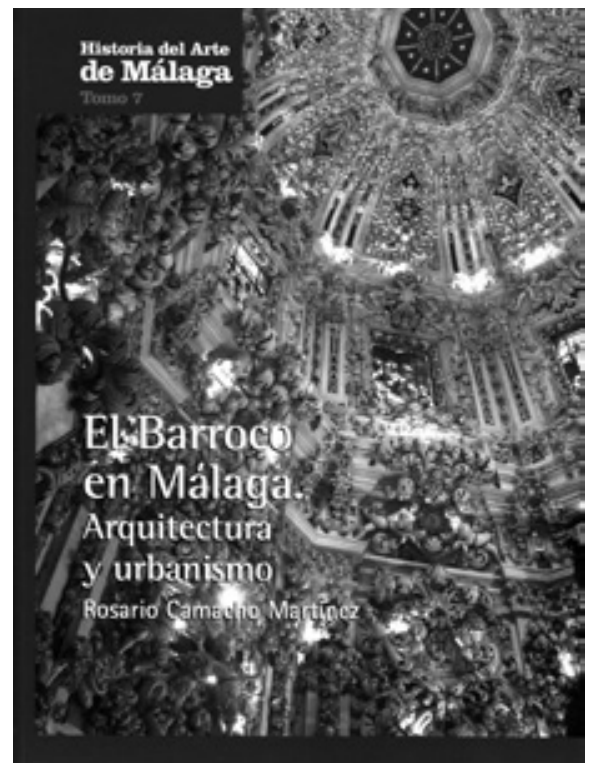

Es unánime la afirmación contundente (y así lo demuestra sobradamente este homenaje), de que la monumental producción científica de Rosario Camacho ha transformado el paisaje de la provincia de Málaga y a todos nos ha dado otros ojos con los que mirar, no solo esta tierra, sino cualquier otra ciudad, cualquier otra manifestación cultural que nos rodea.

Durante décadas hemos asistido a la peor versión de la «tragedia de la cultura" de la que hablara Georg Simmel. Se ha abierto un abismo entre el objeto cultural y el sujeto que lo produce y que lo alimenta de significado; con esa disociación se ha incrementado exponencialmente nuestro desapego por las manifestaciones del pasado. La teoría del patrimonio cultural ha querido restaurar estos lazos a través de la institución, ya sea administrativa o académica, con un éxito loable pero siempre insuficiente. De poco puede servir el adoctrinamiento institucional si la sensibilidad y el compromiso con la cultura se quedan encerrados en las oficinas y en las aulas, si aquellos que la producen y la reciben día a día no están directamente involucrados. 
Esta apuesta inequívoca por la dimensión social del patrimonio cultural (con inevitables reminiscencias de la Institución Libre de Enseñanza), ha estado presente no solo en la producción científica y el magisterio de Rosario, sino también y sobre todo, en su activa colaboración con las administraciones públicas, sus guías de Málaga o su activa presencia en los medios de comunicación locales.

Sus trabajos de dirección en la Guía histórico-artística de Málaga de Arguval, la Guía de Málaga y su provincia de la Fundación Juan Manuel Lara o la enciclopedia de Historia del Arte en Málaga de Diario Sur, no solo han vertido unos vastos conocimientos de la historia y el arte de la ciudad (y de su provincia, según el caso), sino principalmente una experiencia de su legado cultural. Rosario ha sabido transmitir en ellas un espíritu que va más allá del dato o del acontecimiento; no se trata de una descripción concatenada de lugares históricos, sino sobre todo la unidad compleja y orgánica de los lugares de memoria, espacios donde la sociedad puede reconocerse a sí misma y ante los otros, en los que toma consciencia de su duración en el tiempo y donde igualmente puede seguir siendo parte activa.

Efectivamente, Rosario Camacho nos ha abierto amplias ventanas a nuestra realidad inmediata para que sigamos enriqueciendo el patrimonio con nuevos significados, pero desde la responsabilidad necesaria del respeto a la instancia cultural del monumento. Este compromiso ha estado muy presente siempre en sus intervenciones en prensa escrita. Quedan en las hemerotecas numerosas columnas de opinión de su autoría así como entrevistas y testimonios en los que se ha pronunciado activamente a favor de la defensa de la Aduana como Museo para Málaga, del malogrado Museo del Císter, del Patrimonio industrial, o en contra de la desaparición del Silo del Puerto, de las chimeneas de la Misericordia, de la antigua estación de ferrocarril...

En definitiva, la obra de Rosario Camacho ha reconciliado a Málaga con su memoria cultural, y le ha invitado a seguir trabajando en ese vínculo como un valor de ciudadanía y de dignidad. Así, y para concluir, lo expresaba ella misma el día 1 de marzo de 2006, en Diario Sur con un artículo de opinión sobre «El silo de Málaga»:

En el momento que comprendemos que el pasado es una etapa cerrada [...]. Es en ese momento cuando la memoria, entendida como una acción de recuperación, pero en este caso con valor de proyección al futuro, debería haber estrechado sus vínculos con la imaginación, savia nueva y renovadora [...] y dotar de un nuevo uso y de unas bases para construir lo que en un futuro será una memoria renovada. Pero si Málaga tiene miedo a mirar de frente a 


\section{comentarios bibliográficos}

su pasado reciente, probablemente no esté interesada en conservarlo, pues el discurso que todo lo justifica en aras del progreso es indicativo de una sociedad que no tiene herramientas suficientes para identificar su patrimonio, y en definitiva, de generar su memoria, y no hay mejor privilegio social que tener la capacidad de recordar.

\section{Asuntos de Arquitectura y Patrimonio}

Antonio Jesús Santana Guzmán

Historiador del Arte vinculado a la UMA

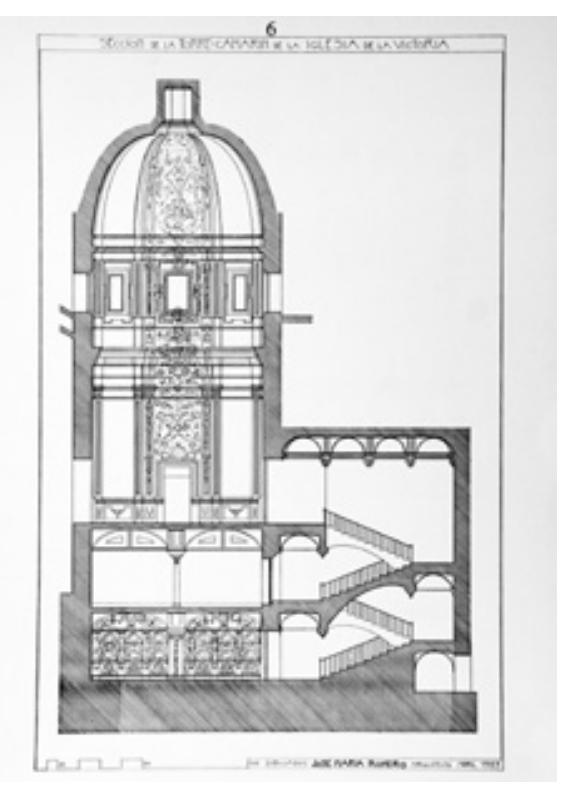

Sección de la Torre-Camarín de la Iglesia de la Victoria, abril de 1985
Mi primer contacto con el mundo de la Historia del Arte llegó a finales de los noventa con una charla sobre la Iglesia del Sagrado Corazón; esa lección me dejó clarísima mi vocación; del mismo modo, el primer texto específico que consulté fue un monográfico en el que se trataba el asunto de la Torre-Camarín de la Victoria. Pues tan solo cinco años después resultaba que la autora de ambas investigaciones, Rosario Camacho Martínez, se convertía en directora de mi tesis doctoral. Por todo esto, es para mí un honor poder contribuir a un homenaje tan merecido para una persona a la que siento (no solo como guía en la docencia, sino también en muchos valores personales) y a la que considero toda una maestra en el más amplio sentido del término.

Aquel monográfico pertenece a una serie titulada Asuntos de Arquitectura, resultado de la intención común del Colegio de Arquitectos y de la 